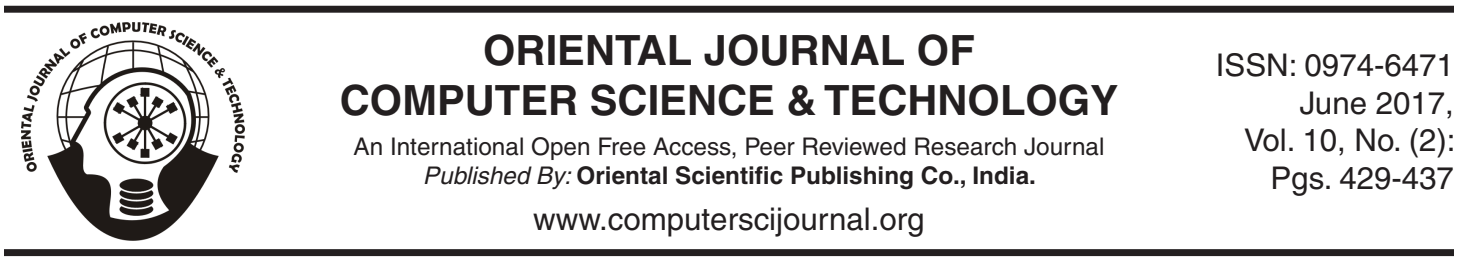

\title{
A Review on Electronic Dictionary and Machine Translation System Developed in North-East India
}

\author{
SAIFUL ISLAM* and BIPUL SYAM PURKAYASTHA
}

Department of Computer Science, Assam University, Silchar, PIN-788011, Assam, India

Corresponding author e-mail: sislam.mca@gmail.com

http://dx.doi.org/10.13005/ojcst/10.02.25

(Received: May 04, 2017; Accepted: May 12, 2017)

\begin{abstract}
Electronic Dictionary and Machine Translation system are both the most important language learning tools to achieve the knowledge about the known and unknown natural languages. The natural languages are the most important aspect in human life for communication. Therefore, these two tools are very important and frequently used in human daily life. The Electronic Dictionary (E-dictionary) and Machine Translation (MT) systems are specially very helpful for students, research scholars, teachers, travellers and businessman. The E-dictionary and MT are very important applications and research tasks in Natural Language Processing (NLP). The demand of research task in E-dictionary and MT system are growing in the world as well as in India. North-East (NE) is a very popular and multilingual region of India. Even then, a small number of E-dictionary and MT system have been developed for NE languages. Through this paper, we want to elaborate about the importance, approaches and features of E-dictionary and MT system. This paper also tries to review about the existing E-dictionary and MT system which are developed for NE languages in NE India.
\end{abstract}

Keywords: Electronic Dictionary, Machine Translation, NE languages, NLP.

\section{INTRODUCTION}

Natural language is the most important communication media for all human beings. Natural language processing is one of the interdisciplinary research areas in Computer Science, Computational Linguistic and Artificial Intelligence. It is a very attractive method for interactions between computers and natural languages. The purpose of NLP is to design and develop software that will analyze, understand, and produce speech or text of natural languages ${ }^{21}$. At present, it is a very demand able research area in computer science that explores how computers can be used to understand and manipulate text or speech of natural languages to do useful things. A 
huge amount of different applications of NLP has been developed in the world as well as in India. The most commonly used applications of NLP are Electronic Dictionary, Machine Translation, Machine Transliteration, Information Retrieval, Morphological Segmentation, Named Entity Recognition, Optical Character Recognition, Part of Speech Tagging, Parsing, Question Answering, Speech Processing, Speech Recognition, Speech Segmentation, Spelling Checker, Wordnet and Word Sense Disambiguation.

The North-East is one of the most linguistically and ethnically diverse regions of India. The NE region is situated between the two great traditions of the Indic Asia and the Mongoloid Asia. The North-East India (NEI) consists of eight states which are Arunachal Pradesh, Assam, Manipur, Meghalaya, Mizoram, Nagaland, Sikkim and Tripura. Each of the states has own culture, language and tradition ${ }^{1,2}$. The people of NEI belong to different communities and each community has different languages. Therefore, NE is also known as multilingual and multicultural region of India. In this situation, E-dictionary and MT system are very important for communication among people of the different communities. A small number of E-dictionary and MT system have been developed for NE languages in India.

In this paper, we discuss the two most important applications of NLP which are developed for NE languages in NE India, namely E-Dictionary and Machine Translation. The E-dictionary and MT systems are tremendous potential and frequently used in human daily life.

\section{North-East Languages}

The natural languages act as a bridge amongst the people and help in creating a bond among their cultures. There are about 220 spoken languages in NEI and these languages are divided into mainly three language families, namely Indo-Aryan, Sino-Tibetan and Austro-Asiatic [2]. The languages of the Indo-Aryan family are Assamese, Bengali and Nepali. The languages of the Austro-Asiatic family are Khasi and Jaintia. The languages of the Sino-Tibetan family are Abor, Adi, Angami, Ao, Apatani, Biate, Bodo, Chakm, Deuri, Garo, Hmar, Hrusso, Karbi, Konyak, Lotha, Meiteilon, Misimi, Mishing, Mizo, Nocte, Nyishi, Rabha, Sema, Tanee, Tangkhul, Tiwa etc. The most commonly speaking languages in NE region are Assamese, Bengali, English, Hindi, Manipuri and Nepali. The Assamese, Bengali, Hindi, Manipuri and Nepali are also five of the 22 recognized languages and English is the associate official language of India [1]. The different languages of the eight states of $\mathrm{NEI}$ are shown in the Table 1.

\section{Electronic Dictionary}

A dictionary is a very important language learning book which contains enormous words of one or more particular languages and the words are arranged alphabetically with their meaning, part-of-speech (POS), synonyms, phonetics and examples. It is a very helpful tool for students, research scholars, teachers, travellers and other people to improve their knowledge about the various languages. The dictionary is divided basically into two broad categories, namely Paper dictionary and Electronic dictionary. The Paper dictionary is also known as hard or printed dictionary and Electronic

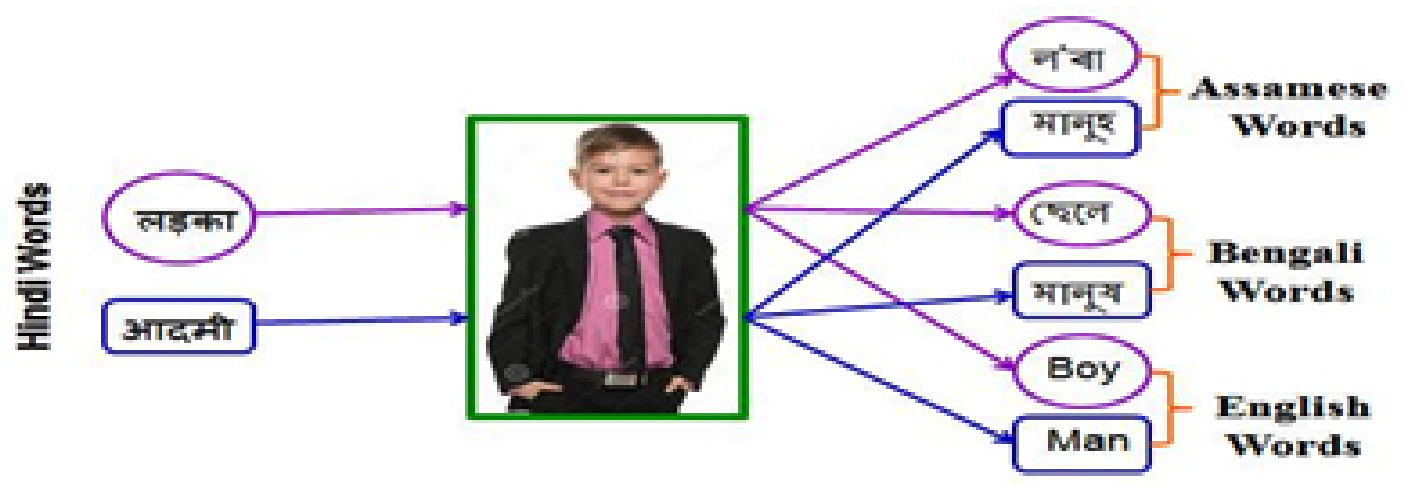

Fig. 1: Example of H-ABE E-dictionary 
dictionary is also known as soft dictionary. The Electronic dictionary (E-dictionary) is one kind of dictionary whose data exist in digital form and can be used through different media. The E-dictionary is the most powerful tool for human to learn about the specific natural languages from anywhere place and any time using computers, smart phone and PDA. It is very convenient to use and tremendously better than paper dictionary. The E-dictionary is an important application of NLP and can be used to implement the other research tasks in NLP like machine translation, wordnet, etc.

\section{Different types of E-dictionary}

Generally, the E-dictionary can be divided into two types as discuss as follows:

\section{Online E-dictionary}

The online E-dictionary can be accessed in digital form through the Internet using web browsers from anywhere place in the world. Therefore, this dictionary is also known as Internet dictionary. It is very convenient to use if there is an Internet connection and large numbers of user can be accessed simultaneously on online.

\section{Offline E-dictionary}

The offline E- dictionary can be accessed through digital computer, personal data assistant and smart mobile phone. This dictionary can be carried and keep backup using compact disk, digital versatile disk, hard disk and pen drive. Therefore, this dictionary is also known as a

Table 1: Different languages of the states of NEI

\begin{tabular}{|c|c|c|}
\hline Name of the States & Official languages & Major Spoken Languages \\
\hline Arunachal Pradesh & English & $\begin{array}{l}\text { Adi, Assamese, Bengali, Hindi, } \\
\text { Mishing, Monpa, Nepali, } \\
\text { Nyishi, Tangsa, Wancho }\end{array}$ \\
\hline Assam & Assamese, & $\begin{array}{c}\text { Assamese, Bengali, Bishnupriya } \\
\text { Manipuri, Bodo, Dimasa, } \\
\text { Hindi, Karbi, Mishing, Nepali, Rabha }\end{array}$ \\
\hline Manipur & $\begin{array}{l}\text { Bengali, Bodo, English } \\
\text { English, Meiteilon (Manipuri) }\end{array}$ & $\begin{array}{l}\text { Bengali, Hindi, Kabui, Kuki, Hmar, } \\
\text { Manipuri, Nepali, Paite, } \\
\text { Tangkhul, Thadou-Kuki }\end{array}$ \\
\hline Meghalaya & English, Garo, Khasi & $\begin{array}{l}\text { Assamese, Bengali, Garo, } \\
\text { Hajong, Hindi, Khasi, } \\
\text { Koch, Nepali, Rabha }\end{array}$ \\
\hline Mizoram & English, Mizo & $\begin{array}{l}\text { Bengali, Chakma, Hindi, Hmar, } \\
\text { Lakher (Mara), Mizo, } \\
\text { Nepali, Pawi, Paite, Tripuri }\end{array}$ \\
\hline Nagaland & English & $\begin{array}{l}\text { Angami, Ao, Assamese, Bengali, } \\
\text { Chakru, Chang, Hindi, Garo, } \\
\text { Kheza, Konyak, Kuki, Lotha, } \\
\text { Nagamese, Phom, Rengma, } \\
\text { Sangtam, Sumi, Yimchungre }\end{array}$ \\
\hline Sikkim & English, Nepali & $\begin{array}{l}\text { Hindi, Lepcha, Limbu, Nepali, } \\
\text { Rai, Sherpa, Sikkimese } \\
\text { (Bhutia), Tamang }\end{array}$ \\
\hline $\begin{array}{l}\text { Tripura } \\
\text { Kokborok }\end{array}$ & $\begin{array}{l}\text { Bengali, English, } \\
\text { Bengali, Bishnupriya Manipuri, } \\
\text { Garo, Halam, Hindi, } \\
\text { Kokborok (Tripuri), } \\
\text { Manipuri, Mogh }\end{array}$ & \\
\hline
\end{tabular}


portable digital dictionary. User can download this type of dictionary through the Internet in his/her own computer or smart phone and can be accessed without the Internet.

According to the languages involve, the E-dictionary can be divided into three categories as below 5 :

\section{Monolingual E-dictionary}

The monolingual E-dictionary is one kind of dictionary where users can look up the meaning of word and other related information of the word like POS, synonyms and examples from one natural language to itself. For example, AssameseAssamese, English-English, Manipuri-Manipuri and so on are monolingual E-dictionary.

\section{Bilingual E-dictionary}

The bilingual E-dictionary is one kind of dictionary where users can look up the meaning of word and other related information of the word like POS, synonyms and examples from a source natural language to a target natural language. For example, Assamese to English, English to Bengali and so on are bilingual E-dictionary.

\section{Multilingual E-dictionary}

The multilingual E-dictionary is one kind of dictionary where users can look up the meaning of word and other related information of the word like POS, synonyms and examples from one natural language to two or more natural languages. For example, Assamese to English and Bengali, English-Manipuri and Nepali, etc. are multilingual E-dictionary.

\section{Different Techniques of E-dictionary}

There are many word search techniques are available to develop the E-dictionary. Different developers use different word search techniques to look up (search) the words from the E-dictionary on both online and offline. The most commonly used word search techniques to develop the E-dictionary are as follows 22 :

$\begin{array}{ll} & \text { Sequential Search Technique } \\ £ & \text { Index Based Search Technique } \\ £ & \text { Binary Search Technique } \\ £ & \text { Incremental Search Technique }\end{array}$

\section{Wildcard Search Technique}

\section{Example of an Electronic Dictionary}

Let us consider, Hindi to Assamese, Bengali and English (H-ABE) a multilingual E-dictionary. In this dictionary, the user can look up the meaning of Hindi word into corresponding Assamese, Bengali and English words as well as other related information of the given word like POS, synonyms and examples. Two examples of Hindi words and their corresponding meanings in Assamese, Bengali and English words are shown in figure 1.

\section{E-dictionary Developed in NEI}

In this section, we discuss about the existing electronic dictionaries which are developed in NEI for NE languages. From the literature survey, it has been found that a large number of paper dictionaries have been compiled by many lexicographers for the maximum numbers of major languages of $\mathrm{NEI}$. At present, due to expansion of computer and Internet, a small number of E-dictionary has been developed on both online and offline for the languages of NEI. In this paper, some of the electronic dictionaries which have been developed for NE languages in NE India are shown in Table 2.

\section{Machine Translation}

Machine Translation (MT) is one of the most important applications and research tasks of NLP which investigates the use of software to translate text or speech from one natural language to another natural language using computers with or without human assistance. The MT system which generates translation between two specific languages are called bilingual MT systems. The bilingual MT system may be either one direction or both directions. The machine translation is as old as that of computers and it was the first computer based applications related to NLP. The MT system generally started in the year 1950, although work can be found from earlier periods. The first non-military computers were developed in 1947, from that time the idea was proposed to translate text from a source language (SL) to a target language ( $T L)$ using a computer [14]. At present, it is a very challenging research tasks in the area of computational linguistics and NLP in the world as well as in India. The research scenario in India is relatively young and machine 
translation gained momentum in India only from 1980 onwards with institutions like IIT Kanpur, IIT Bombay, IIIT Hyderabad, University of Hyderabad, NCST Mumbai. The Technology Development for Indian Languages (TDIL), Centre for Development of Advanced Computing (CDAC) and Ministry of Communications and Information Technology are playing a major role in developing the MT systems [16]. The MT system is very important for human nowadays for the following reasons:

- Huge amount of text can be translated from one natural language to another natural language using a MT system which is not possible by human translators.

- It can be used to reduce the human efforts and to give the translation results quickly.

- The use of MT system can increase the volume and speed of translation throughput.

- Manual translation for translating the huge amount of text document is not only time consuming, but also need a more expense. Therefore, MT system can be used to save time and reduce cost.

\section{Problems with Machine Translation}

The machine translation is a very difficult research task in NLP due to some problems with it like Word Order (WO), Word Sense Ambiguity (WSD), Part-Of-Speech (POS) and Idioms. These problems are different between different languages. The problems of MT are discussed as below for English and Bodo languages:

\section{Word Order}

Word order is different between English and Bodo languages.

English WO: subject(S)-verb(V)-object(O)

Bodo WO: subject(S)-object(O)-verb(V)

For example:

English: I(S) eat(V) rice(0).

\section{WO=SV0}

\section{Bodo : आ $(S)$ औंखाम $(0)$ जायी $(\mathrm{V}) \mid \quad W 0=S O V$}

\section{Word sense ambiguity}

The same word may have different meaning or sense when being translated to another language.

For example:

\section{English: Plont means Tree of Factory}

Bodo: Plantmeans बिफां or कारख्राना

\section{POS}

The POS is different between English and Bodo languages. Pre-position is used in English and Post-position is used in Bodo language.

For example:

English: Anil has sat on the table (O).

Bodo: अनिला आरांगा (O) सायाव जिरायबाय।

\section{Idioms}

Meaning of idiom is different between English and Bodo languages.

For example:

$$
\begin{gathered}
\text { English: 'as well as' } \\
\text { Bodo: 'धरो' }
\end{gathered}
$$

\section{Different approaches of MT}

There are various approaches of machine translation. Generally, the approaches of MT can be divided into main three categories [12, 13], namely Human Translation with Machine Support, Machine Translation with Human Support and Fully Automated (Automatic) Machine Translation. Again the Fully Automated (Automatic) MT can be divided into seven categories, namely Empirical (or Corpus Based)

MT, Knowledge Based MT, Hybrid MT, Rule Based MT (RBMT), Principle Based MT and Online Interactive MT. The Empirical (or Corpus Based) MT can be divided into two categories, namely Statistical Machine Translation (SMT) and Example Based Machine Translation (EBMT). The SMT approach can also be divided into three categories, namely, Word Based Translation, Phrased Based Translation and Hierarchical Phrased Based Translation. The RBMT can also be divided into three categories, namely Direct MT, Transfer MT and Interlingua MT.

\section{Example of a MT System}

Let us consider, English to Assamese $(E-A)$ is a bilingual MT system. In this system, users can translate the huge amount of text of English 
Table 2: E-dictionary developed for NE languages

\begin{tabular}{|c|c|c|c|c|}
\hline Title of the E-dictionary & Languages & Developers & Place/ Institution & Year \\
\hline \multicolumn{5}{|l|}{ English-Assamese-Bodo } \\
\hline \multicolumn{5}{|l|}{ Trilingual E-dictionary } \\
\hline \multicolumn{5}{|l|}{ (http://www.iitg.ernet.in } \\
\hline /rcilts/dictionary.html) & Assamese, & Resource Centre & IIT Guwahati, & 2004 \\
\hline Multilingual Online & Bodo, English & for Indian Language & Assam & \\
\hline Dictionary (English to & & Technology Solutions & & \\
\hline \multicolumn{5}{|l|}{ NE languages) } \\
\hline [www.xobdo.org] & $\begin{array}{l}\text { Assamese, } \\
\text { Bishnupriya Manipuri,Bodo, } \\
\text { Dimasa, English, Garo, } \\
\text { Hmar, Karbi, Khasi, } \\
\text { Meiteilon, Mising }\end{array}$ & $\begin{array}{l}\text { Bikram M } \\
\text { Baruah }\end{array}$ & $\begin{array}{l}\text { Assam, } \\
\text { India }\end{array}$ & 2006 \\
\hline \multicolumn{5}{|l|}{$\begin{array}{l}\text { Bilingual Dictionary } \\
\text { of Words \& Phrases }\end{array}$} \\
\hline [www.bengali-dictionary.com] & Bengali, English & Subhamay Ray & Tripura, India & 2006 \\
\hline $\begin{array}{l}\text { Nepali to Hindi Bilingual } \\
\text { Electronic Dictionary [9] }\end{array}$ & Hindi, Nepali & $\begin{array}{l}\text { Shantanu Kar, } \\
\text { Alok Chakrabarty }\end{array}$ & Silchar, Assam & 2011 \\
\hline Building Multilingual & Assamese, & Shikhar & Gauhati & 2012 \\
\hline $\begin{array}{l}\text { Lexical Resources [10] } \\
\text { Manipuri-English Bilingual }\end{array}$ & Bodo, Hindi & Kr. Sarma et al. & University, Assam & \\
\hline E-dictionary [4] & English, Manipuri & S. Poireiton & Assam & 2012 \\
\hline Mizo-English-Mizo & & Meitei et al. & University, Silchar & \\
\hline \multicolumn{5}{|l|}{ Online Dictionary } \\
\hline $\begin{array}{l}\text { [http://www.freelang.net } \\
\text { /online/mizo.php] }\end{array}$ & $\begin{array}{l}\text { English, Mizo } \\
\text { Figueiredo }\end{array}$ & $\begin{array}{l}\text { Renato B. } \\
\text { India }\end{array}$ & Mizoram, & 2014 \\
\hline $\begin{array}{l}\text { Web Enabled Multilingual } \\
\text { Manipuri Dictionary [3] }\end{array}$ & English, Hindi, Manipuri & $\begin{array}{c}\text { Yumnam } \\
\text { Bablu Singh }\end{array}$ & $\begin{array}{l}\text { Assam University, } \\
\text { Silchar, Assam }\end{array}$ & 2015 \\
\hline $\begin{array}{l}\text { Kokborok-English } \\
\text { Bilingual Electronic } \\
\text { Dictionary [8] }\end{array}$ & English, Kokborok & $\begin{array}{l}\text { Partha Sarkar, Bipul } \\
\text { Syam Purkayastha }\end{array}$ & $\begin{array}{c}\text { Assam } \\
\text { University, Assam }\end{array}$ & 2015 \\
\hline $\begin{array}{l}\text { English and English-Assamese } \\
\text { E-dictionary (App for Android OS) }\end{array}$ & Assamese, English & Manabendra Gogoi & Assam & 2015 \\
\hline $\begin{array}{l}\text { Multilingual Assamese Electronic } \\
\text { Dictionary (Assamese to } \\
\text { Bengali, English and Hindi) [7] }\end{array}$ & $\begin{array}{l}\text { Assamese, Bengali, } \\
\text { English, Hindi }\end{array}$ & $\begin{array}{l}\text { Saiful Islam, Bipul } \\
\text { Syam Purkayastha }\end{array}$ & $\begin{array}{c}\text { Assam } \\
\text { University, Silchar }\end{array}$ & 2015 \\
\hline $\begin{array}{l}\text { English to Assamese, Bengali and } \\
\text { Hindi Multilingual }\end{array}$ & $\begin{array}{l}\text { nd Assamese, Bengali, } \\
\text { English, Hindi }\end{array}$ & Saiful Islam & $\begin{array}{l}\text { Assam University, } \\
\text { Silchar, Assam }\end{array}$ & 2016 \\
\hline Electronic Dictionary [5] & & & & \\
\hline English to Nepali & & & & \\
\hline $\begin{array}{l}\text { Online Dictionary } \\
\text { [www.englishne } \\
\text { palidictionary.com] }\end{array}$ & English, Nepali & NA & Sikkim, & 2016 \\
\hline Multilingual Bengali Electronic & & & India & \\
\hline Dictionary (Bengali to Assamese, & Assamese, Bengali, & Saiful Islam, Bipul & m Universit & 2016 \\
\hline
\end{tabular}


English and Hindi) [6]

Assamese to Bengali

Bilingual E-Dictionary Using

Sequential Search Technique [20] Assamese, Bengali

Saiful Islam. Bipul Assam University, 2016

Syam Purkayastha Silchar, Assam

\begin{tabular}{|c|c|c|}
\hline English [SL] & Machine [Computer] & Assamese [TL] \\
\hline $\begin{array}{l}\text { Assam is a beautiful } \\
\text { Place. }\end{array}$ & \multirow{4}{*}{$\begin{array}{l}\text { ENGLISH-ASSAMESE } \\
\text { TRAMELATION } \\
\text { DR }\end{array}$} & অসম এখন ধুনীয়া ঠাই। \\
\hline I love my mothen: & & মই মোব মাক ভাল পাত্ট। \\
\hline $\begin{array}{l}\text { Guwahati is a big } \\
\text { city of Assam. }\end{array}$ & & $\begin{array}{l}\text { ঞवाহাঁীী অসयব এখন } \\
\text { ডাঙব নগব। }\end{array}$ \\
\hline $\begin{array}{l}\text { India is famous for } \\
\text { Tajmahal. }\end{array}$ & & $\begin{array}{l}\text { ভাবত তাজমহলনব বাবে } \\
\text { বিখ্যাত। }\end{array}$ \\
\hline
\end{tabular}

Fig. 2: Example of sentences in E-A MT system

Table 3: MT system developed in NEI

\begin{tabular}{|c|c|c|c|c|c|}
\hline Title of the MT system & Languages & Technique & Developers & Place/Institution & Year \\
\hline $\begin{array}{l}\text { English to Assamese } \\
\text { and Manipuri } \\
\text { MT system [14] }\end{array}$ & $\begin{array}{l}\text { Assamese, } \\
\text { English, Manipuri }\end{array}$ & $\begin{array}{l}\text { EBMT, } \\
\text { RBMT }\end{array}$ & $\begin{array}{c}\text { IIT } \\
\text { Guwahati }\end{array}$ & $\begin{array}{l}\text { Assam, } \\
\text { India }\end{array}$ & 2004 \\
\hline $\begin{array}{l}\text { Assamese to } \\
\text { English MT system [11] }\end{array}$ & $\begin{array}{l}\text { Assamese, } \\
\text { English }\end{array}$ & SMT & $\begin{array}{c}\text { Pranjal Das, } \\
\text { Kalyanee K. Baruah }\end{array}$ & $\begin{array}{c}\text { Gauhati } \\
\text { University, Assam }\end{array}$ & 2014 \\
\hline $\begin{array}{l}\text { English to Assamese } \\
\text { MT system [15] }\end{array}$ & $\begin{array}{l}\text { Assamese, } \\
\text { English }\end{array}$ & SMT & M. T. Singh et al. & $\begin{array}{c}\text { Dibrugarh } \\
\text { University, Assam }\end{array}$ & 2014 \\
\hline $\begin{array}{l}\text { Machine Translation } \\
\text { for Assamese-English } \\
\text { Using Apertium [17] }\end{array}$ & $\begin{array}{l}\text { Assamese, } \\
\text { English }\end{array}$ & RBMT & Pranjal Das et al. & $\begin{array}{c}\text { Gauhati } \\
\text { University, Assam }\end{array}$ & 2014 \\
\hline Bengali to Assamese & Assamese, & SMT & $\begin{array}{l}\text { Nayan Jyoti Kalita, } \\
\text { Baharul Islam }\end{array}$ & $\begin{array}{l}\text { Royal School of } \\
\text { Engineering and }\end{array}$ & 2015 \\
\hline $\begin{array}{l}\text { MT system } \\
\text { using Moses [12] }\end{array}$ & Bengali & & & Technology, Assam & \\
\hline $\begin{array}{l}\text { English to Nepali } \\
\text { Statistical }\end{array}$ & English, & SMT & Abhijit Paul, Bipul & Assam University, & 2016 \\
\hline $\begin{array}{l}\text { Machine Translation } \\
\text { System [18] }\end{array}$ & Nepali & & Syam Purkayastha & Silchar, Assam & \\
\hline $\begin{array}{l}\text { English to Bodo } \\
\text { Phrase Based }\end{array}$ & English, & SMT & Saiful Islam, Bipul & Assam University, & 2016 \\
\hline $\begin{array}{l}\text { Statistical Machine } \\
\text { Translation [19] }\end{array}$ & Bodo & & Syam Purkayastha & Silchar, Assam & \\
\hline
\end{tabular}

language (SL) into Assamese language (TL) using computers. Some examples of sentences in English to Assamese MT system are shown in figure 2 .
Machine Translation System Developed in NEI

In this section, we discuss about the existing machine translation systems which are 
developed in NEI for NE languages. From the literature survey, it has been found that a very small number of MT system has been developed in NEI using different approaches by different developers. In this paper, some of the MT systems which have been developed for North-East languages in NEI are shown in Table 3.

\section{CONCLUSION}

Electronic dictionary is a powerful dictionary whose data is found in digital form and can be accessed through online and offline from anywhere place using a computer, smart phone and PDA. Through this dictionary, a user can look up the meaning of word and other related information of the word like POS, synonyms and examples from a source natural language to the target natural languages. Machine translation is the process of automatic translation of text from a source natural language to another natural language using computers on both online and offline.
Through the MT system, used can translate huge amount of words or phrases or sentences from a specific natural language to another natural language. The E-dictionary and MT system are the tremendously helpful for people to extend their knowledge about the known and unknown natural languages. These applications are also very important in NLP to implement other research tasks related to NLP. The main purpose of this paper is to focus on the existing E-dictionary and MT system which are developed for NE languages in the NE India. A small number of E-dictionary and MT system have been developed for

NE languages in the NEl. Nowadays, some research scholars are working on E-dictionary and MT system for NE languages in India as well as in the NE region. Since, NE is a multilingual region in India. Therefore, the E-dictionary and MT system will be helpful for NE people as well as other people of India and abroad.

\section{REFERENCES}

1. Government of India: $47^{\text {th }}$ Report (June 2008 to July 2010) of the Commissioner for Linguistic Minorities: Ministry of Minority Affairs, India, 2011.

2. T. Raatan: History, Religion and Culture of North East India, Isha book, Delhi, 2006.

3. Singh, Y. B.: Corpus and wordnet based Multilingual Manipuri Dictionary, academia. edu.

4. Meitei, S. P., Ningombam,S., Devi, H. M., Purkayastha, B. S.: A Manipuri-English Bilingual Electronic Dictionary: Design and Implementation. International Journal of Engineering and Innovative Technology, Vol.2, No.1, 2012.

5. Islam, S.: An English To Assamese, Bengali and Hindi Multilingual E-Dictionary. International Journal of Current Engineering and Scientific Research, Vol.3, No. 9, 2016.

6. Islam, S., Purkayastha,B. S.: Multilingual Bengali Electronic Dictionary Using Sequential Search Technique. International Journal of Innovative Research in Science,
Engineering and Technology, Vol. 5, No. 3, pp. 3307-3314, 2016.

7. Islam, S., Purkayastha,B. S.: Development of Multilingual Assamese Electronic Dictionary. International Journal of Computer Science and Information Technologies, Vol. 6No. 6, pp. 5446-5452, 2015.

8. Sarkar, P., Purkayastha,B. S.:Morphological Analyzer in the Development of Bilingual Dictionary (Kokborok-English) - An Analysis for Appropriate Method and Approach. International Journal of Engineering and Innovative Technology, Vol. 4, No.10, 2015.

9. Kar, S., Chakrabarty, A.: Expansion of the First Hindi-Nepali Word-Net based Bilingual Dictionary and the advancement of the Human-Machine Interface. Special Issue of International Journal of Computer Applications, 2011.

10. Sarma , S. K., Sarmah, D., Brahma , B., Mahanta, M., Bharali, H., Saikia, U.: Building Multilingual Lexical Resources Using Wordnets: Structure, Design and 
Implementation. Proceedings of the 3rd Workshop on Cognitive Aspects of the Lexicon (CogALex-III), pp. 161-170, COLING, Mumbai, 2012.

11. Das, P., Baruah, K. K.: Assamese to English Statistical Machine Translation Integrated with a Transliteration Module. International Journal of Computer Applications, Vol. 100, No. 5, pp. 20-24, 2014.

12. Kalita, N. J., Islam, B.: Bengali to Assamese Statistical Machine Translation using Moses (Corpus Based). Proceedings of the International Conference on Cognitive Computing and Information Processing, 2015.

13. Godase, A., Govilkar, S.: Machine Translation Development for Indian Languages and its Approaches. International Journal on Natural Language Computing, Vol. 4, No. 2, pp. 5574, 2015.

14. Antony, P.J.: Machine Translation Approaches and Survey for Indian Languages. Computational Linguistics and Chinese Language Processing, Vol. 18, No. 1, pp. 47-78, 2013.

15. Singh, M. T., Borgohain, R., Gohain, S.: English-Assamese Machine Translation System. International Journal of Computer Applications, Vol.93 No. 4, pp. 1-6 , 2014.

16. Sanyal, S., Borgohain, R.: Machine Translation system in India: Annals of Faculty Engineering Hunedoara - International
Journal of Engineering, pp. 137-142, 2013.

17. Das, P., Baruah, K. K., Hannan, A., Sarma, S. K.: Rule Based Machine Translation for Assamese-English Using Apertium. International Journal of Emerging Technologies in Computational and Applied Sciences, Vol.8, No.5, pp. 401-406, 2014

18. Abhijit, P., Purkayastha, B.S.:English to Nepali Statistical Machine Translation System. Proceedings of the International Conference on Computing and Communication Systems, NEHU, Meghalaya, Springer, 2016 (Accepted and presented, waiting for publish).

19. Islam, S., Purkayastha,B. S.: English to Bodo Phrase Based Statistical Machine Translation. Proceedings of the $10^{\mathrm{Th}}$ International Conference On Advanced Computing \& Communication Technologies, APIIT, India, Springer, 2016 (Accested and presented, waiting for publish).

20. Islam, S., Purkayastha,B. S.: Assamese to Bengali Bilingual E-Dictionary Using Sequential Search Technique. Proceedings of the DST Sponsored National Seminar On Computational Research And Its Development In Experimental Sciences. Journal of Science forum, Vol.5 NO.1 pp. 90-98, 2016.

21. Kumar, E.: Natural Language Processing (Book), 2011. Lew, R.: Online dictionary skills, Adam Mickiewicz University, 2013. 